\title{
Low BCL7A expression predicts poor prognosis in ovarian cancer
}

\author{
Ziqian Sun ${ }^{1 \dagger}$, Liang Sun ${ }^{2+}$, Miao He ${ }^{3}$, Ying Pang ${ }^{1}$, Zhaoying Yang ${ }^{2^{*}}$ and Junrong Wang ${ }^{1^{*}}$ (D)
}

\begin{abstract}
Background and objective: Ovarian cancer is a common gynaecological cancer with a poor prognosis that poses a serious threat to human life and health. It is essential to explore the possible prognostic biomarkers of ovarian cancer. As an important tumour suppressor gene, BCL7A actively participates in the growth of tumours. We aimed to study the prognostic role of BCL7A in ovarian cancer.

Results: Through data mining of RNAseq data from the Cancer Genome Atlas database (TCGA), we explored the clinical relevance of BCL7A mRNA expression. As a result, we found that BCL7A is expressed at low levels in ovarian cancer tissues and is correlated with survival status. Survival analysis showed that, compared with those who had higher levels of BCL7A expression, patients with ovarian cancer and low levels of BCL7A generally had shorter overall/relapse-free survival times. Cox regression models showed that low BCL7A expression could be used as an independent prognostication factor for ovarian cancer patients.
\end{abstract}

Conclusions: Low BCL7A expression is an independent risk factor for poor prognosis in ovarian cancer patients.

Keywords: Ovarian cancer, Prognosis, BCL7A, Data mining

\section{Introduction}

Ovarian cancer is a common gynaecological cancer; its mortality rate ranks first among gynaecological tumours and it poses a serious threat to human life and health $[1$, 2]. In most cases, ovarian cancer is usually detected in advanced stages, so even with advanced therapeutic strategies, such as targeted therapy, chemoradiotherapy, and combined chemotherapy, the overall 5-year survival rate of ovarian cancer is still poor [3-5]. Therefore, it is essential to explore the possible prognostic biomarkers of ovarian cancer.

As a key molecule of chromatin remodelling, BCL7A is involved in the process of carcinogenesis. BCL7A is expressed in the ovary, brain, lymph nodes and other tissues. The gene is located on chromosome 12q24.31, and 1 natural variant has been found so far. BCL7A plays an important role in human cancer. It has been found that

\footnotetext{
*Correspondence: zhaoyingyang@163.com; junrongwang_2019@yeah.net

Ziqian Sun and Liang Sun are First author.

2Department of Breast Surgery, China-Japan Union Hospital of Jilin University,

126 Xiantai Street, Changchun 130033, People's Republic of China

'Department of Gynaecology and Obstetrics, China-Japan Union Hospital of Jilin University, 126 Xiantai Street, Changchun 130033, People's Republic of China

Full list of author information is available at the end of the article
}

Myc and IgH are directly involved in the three-way gene translocation of Burkitt lymphoma cell lines, which may contribute to the progression of Burkitt lymphoma [6, 7]. In addition, BCL7A was found to be highly methylated in patients with cutaneous T-cell lymphoma and was identified as a marker of a poor prognosis in early-stage cutaneous T-cell lymphoma patients [8]. However, the role of BCL7A in ovarian cancer remains unclear.

To further evaluate the clinical significance of BCL7A in the prognosis of ovarian cancer patients, we examined the differential expression of BCL7A mRNA in ovarian cancer by exploring the Cancer Genome Atlas database (TCGA). The chi-square test and Fisher's exact test were used to evaluate the clinical correlation. Survival analysis and a Cox regression model were employed to identify the correlation between BCL7A and ovarian cancer patients' survival rate.

\section{Results \\ Data overview \\ BCL7A expression data and clinical features from the TCGA database, including age, lymphatic invasion, stage, histologic grade, subdivision, new type, longest}


dimension, sample type, vital status and BCL7A expression, are shown in Table 1.

\section{Differential expression of BCL7A in ovarian cancer}

Boxplots revealed that lower BCL7A expression was found in ovarian cancer tissues compared with normal ovarian tissues (Fig. 1). In addition, BCL7A expression gradually decreased with an increasing histologic grade.

We used the median of BCL7A expression as a cut-off to divide patients into a BCL7A high-expression group and a low-expression group, and there was no difference in the clinicopathological parameters between the two groups (Table 2).

A decrease in BCL7A expression is associated with a poor overall survival of ovarian cancer

As shown in Fig. 2, patients with a shorter overall survival time had particularly low expression of BCL7A ( $P$ $=0.034)$, which was consistent with the results of subgroup analysis, especially for advanced stage $(P=0.012)$, G3 and G4 $(p=0.0097)$, young patients $(p=0.038)$ and older patients $(p=0.049)$.

A univariate Cox model showed that age and BCL7A expression were two survival related variables. A multivariate Cox model suggested that low BCL7A expression was an independent risk factor for ovarian cancer patients' overall survival ( $\mathrm{HR}=1.52, P=0.005$, Table 3 ).

The decrease in BCL7A expression is associated with poor relapse-free survival in ovarian cancer

As shown in Fig. 3, patients with a shorter relapse-free survival time had particularly low expression of BCL7A $(P=0.067)$, which was consistent with the results of subgroup analysis, especially in advanced stage $(P=0.014), \mathrm{G} 3$ and G4 $(p=0.0014)$, and young patients $(p=0.003)$.

A univariate Cox model showed that BCL7A expression was the only relapse related variable. A multivariate Cox model suggested that low BCL7A expression was an independent risk factor for ovarian cancer patients' relapse-free survival $(\mathrm{HR}=3.65, P=0.011$, Table 4$)$.

\section{Discussion}

Although the research on gynaecological cancer treatment technology is developing rapidly, predicting the outcome of ovarian cancer is still obscure [9]. So far, the treatment of ovarian cancer is mainly based on surgery and chemotherapy $[10,11]$. Therefore, it is urgent to find novel biomarkers to predict the outcome of ovarian cancer, which can be used develop targeted therapy for ovarian cancer, especially in its early stages, to improve its survival rate and the patients' quality of life. In this study, we found that the overall survival time of ovarian cancer patients was
Table 1 The baseline information of ovarian cancer patients from TCGA database

\begin{tabular}{|c|c|}
\hline characteristics & Numbers.of.cases... \\
\hline \multicolumn{2}{|l|}{ age } \\
\hline$<55$ & 113(36.69) \\
\hline$>=55$ & 195(63.31) \\
\hline \multicolumn{2}{|l|}{ subdivision } \\
\hline NA & $17(5.52)$ \\
\hline Bilateral & $212(68.83)$ \\
\hline Left & $37(12.01)$ \\
\hline Right & $42(13.64)$ \\
\hline \multicolumn{2}{|l|}{ stage } \\
\hline NA & $2(0.65)$ \\
\hline I & $1(0.32)$ \\
\hline$\|$ & $22(7.14)$ \\
\hline III & 245(79.55) \\
\hline IV & $38(12.34)$ \\
\hline \multicolumn{2}{|l|}{ longest dimension } \\
\hline large & $124(46.1)$ \\
\hline small & 145(53.9) \\
\hline \multicolumn{2}{|l|}{ lymphatic invasion } \\
\hline NA & 180(58.44) \\
\hline NO & $44(14.29)$ \\
\hline YES & $84(27.27)$ \\
\hline \multicolumn{2}{|l|}{ histologic grade } \\
\hline NA & $2(0.65)$ \\
\hline G1 & $1(0.32)$ \\
\hline G2 & $37(12.01)$ \\
\hline G3 & $261(84.74)$ \\
\hline G4 & $1(0.32)$ \\
\hline GB & $2(0.65)$ \\
\hline GX & $4(1.3)$ \\
\hline \multicolumn{2}{|l|}{ sample type } \\
\hline Primary Tumor & 303(98.38) \\
\hline Recurrent Tumor & $5(1.62)$ \\
\hline \multicolumn{2}{|l|}{ vital status } \\
\hline DECEASED & 184(59.74) \\
\hline LIVING & $124(40.26)$ \\
\hline \multicolumn{2}{|l|}{ BCL7A } \\
\hline high & $154(50)$ \\
\hline low & $154(50)$ \\
\hline
\end{tabular}

shorter when BCL7A was expressed at low levels. A Cox regression model showed that low expression of BCL7A was an independent risk factor for a poor outcome of ovarian cancer patients. 


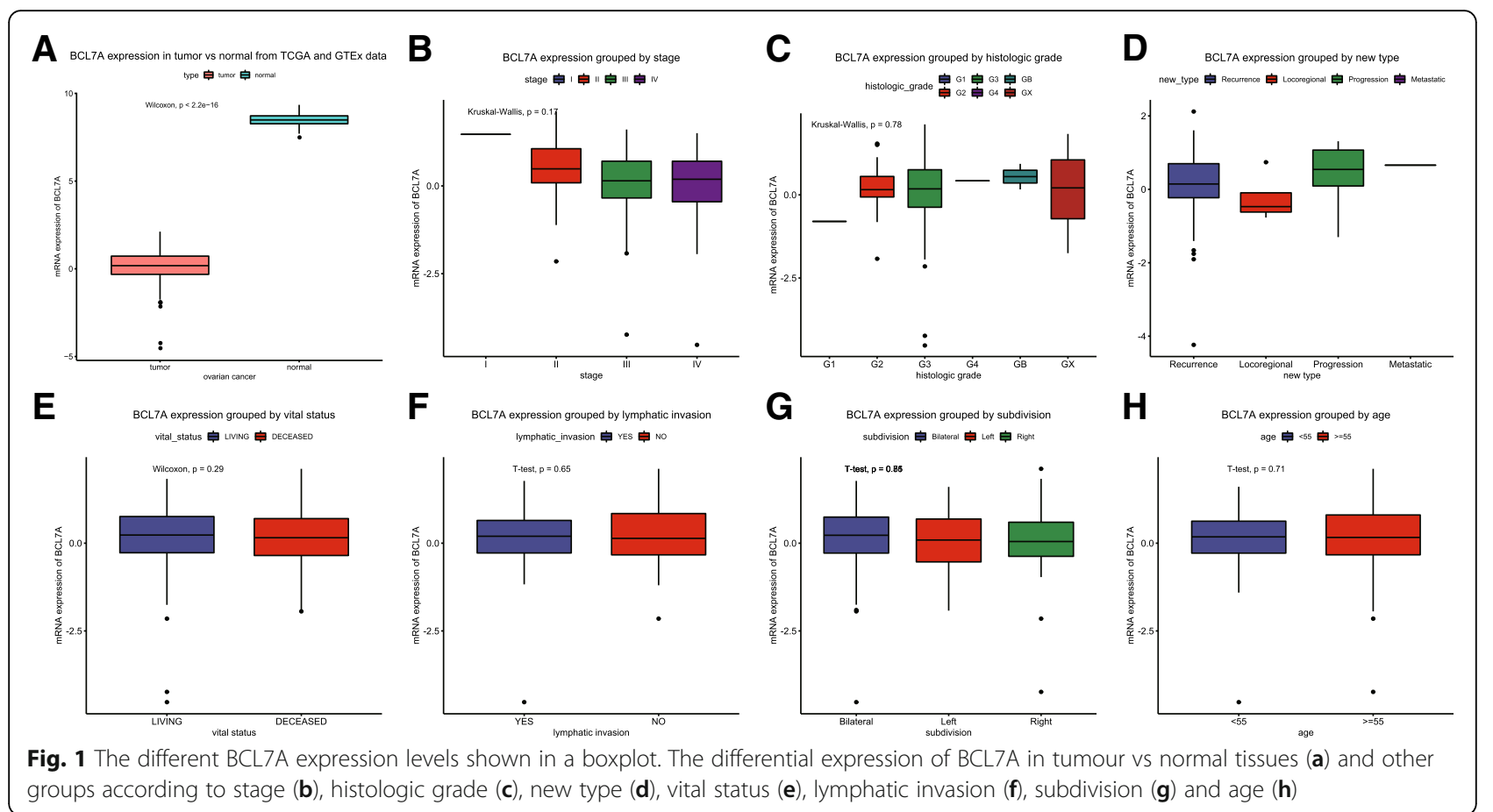

Table 2 The correlation between BCL7A mRNA expression and clinical parameters

\begin{tabular}{|c|c|c|c|c|c|c|c|c|}
\hline \multirow[b]{2}{*}{ Parameter } & \multirow[b]{2}{*}{ Variable } & \multirow[b]{2}{*}{$\mathrm{N}$} & \multicolumn{4}{|c|}{ BCL7A mRNA expression } & \multirow[b]{2}{*}{$x^{2}$} & \multirow[b]{2}{*}{ Pvalue } \\
\hline & & & high & $\%$ & low & $\%$ & & \\
\hline \multirow[t]{2}{*}{ age } & $<55$ & 113 & 57 & $(37.01)$ & 56 & $(36.36)$ & 0 & 1 \\
\hline & $>=55$ & 195 & 97 & $(62.99)$ & 98 & $(63.64)$ & & \\
\hline \multirow[t]{3}{*}{ subdivision } & Bilateral & 212 & 111 & (77.08) & 101 & $(68.71)$ & 3.0653 & 0.216 \\
\hline & Left & 37 & 17 & $(11.81)$ & 20 & $(13.61)$ & & \\
\hline & Right & 42 & 16 & $(11.11)$ & 26 & $(17.69)$ & & \\
\hline \multirow[t]{4}{*}{ stage } & I & 1 & 1 & $(0.65)$ & 0 & (0) & 2.8364 & 0.4175 \\
\hline & $\|$ & 22 & 14 & $(9.15)$ & 8 & $(5.23)$ & & \\
\hline & III & 245 & 119 & (77.78) & 126 & $(82.35)$ & & \\
\hline & IV & 38 & 19 & $(12.42)$ & 19 & $(12.42)$ & & \\
\hline \multirow[t]{2}{*}{ longest dimension } & large & 124 & 67 & $(49.26)$ & 57 & $(42.86)$ & 0.8682 & 0.3515 \\
\hline & small & 145 & 69 & $(50.74)$ & 76 & (57.14) & & \\
\hline \multirow[t]{2}{*}{ lymphatic invasion } & NO & 44 & 19 & (31.15) & 25 & $(37.31)$ & 0.2995 & 0.5842 \\
\hline & YES & 84 & 42 & $(68.85)$ & 42 & $(62.69)$ & & \\
\hline \multirow[t]{6}{*}{ histologic grade } & G1 & 1 & 0 & (0) & 1 & $(0.65)$ & 2.0309 & 0.8449 \\
\hline & G2 & 37 & 18 & $(11.76)$ & 19 & $(12.42)$ & & \\
\hline & G3 & 261 & 131 & $(85.62)$ & 130 & $(84.97)$ & & \\
\hline & G4 & 1 & 1 & $(0.65)$ & 0 & (0) & & \\
\hline & GB & 2 & 1 & $(0.65)$ & 1 & $(0.65)$ & & \\
\hline & GX & 4 & 2 & $(1.31)$ & 2 & $(1.31)$ & & \\
\hline \multirow[t]{2}{*}{ sample type } & Primary Tumor & 303 & 152 & $(98.7)$ & 151 & (98.05) & 0 & 1 \\
\hline & Recurrent Tumor & 5 & 2 & (1.3) & 3 & $(1.95)$ & & \\
\hline \multirow[t]{2}{*}{ vital status } & DECEASED & 184 & 89 & $(57.79)$ & 95 & $(61.69)$ & 0.3375 & 0.5613 \\
\hline & LIVING & 124 & 65 & $(42.21)$ & 59 & $(38.31)$ & & \\
\hline
\end{tabular}




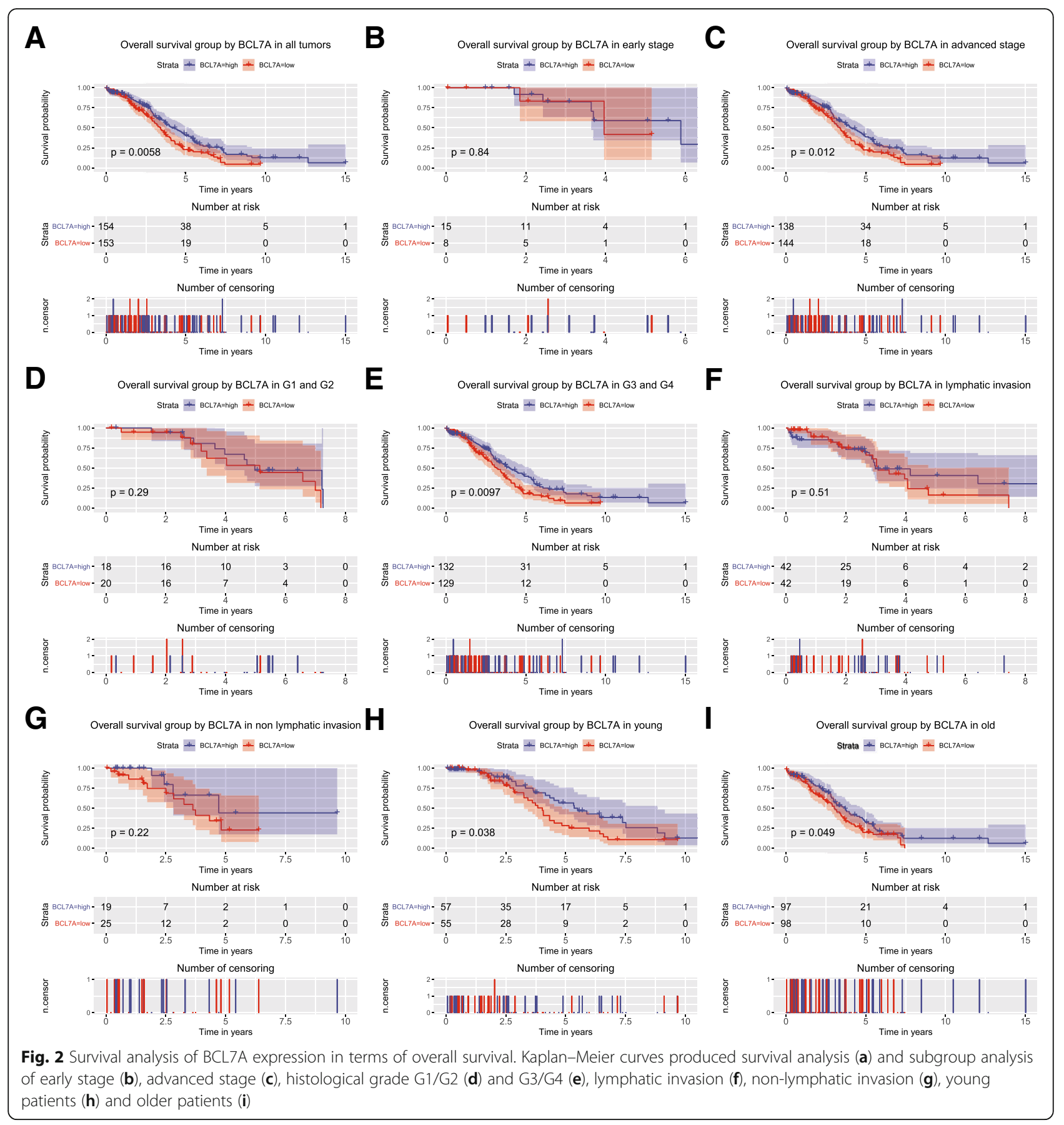

BCL7A was originally cloned from the chromosome translocation of the Burkitt lymphoma cell line [7] and it can interact with SWI/SNF components, suggesting that BCL7A participates in the progression of cancer cells by chromatin remodelling [12]. Recent studies have found that BCL7A expression is increased in diffuse large B-cell lymphoma (DLL) [13] but decreased in mycosis fungoides (MF) and peripheral T-cell lymphoma (PTCL) [14, 15]. Unlike these studies, we have found that BCL7A expression was downregulated in ovarian cancer tissues compared with normal ovarian tissues, which might be due to the different expression and functions of BCL7A in different tissues. In addition, the boxplots showed that the expression of BCL7A had no significant difference in regard to age, lymphatic invasion, stage, histologic grade, subdivision, new type, longest dimension, sample type, or vital status. Therefore, it is necessary to 
Table 3 Univariate and Multivariate Cox analysis of overall survival in ovarian cancer

\begin{tabular}{|c|c|c|c|c|c|c|}
\hline \multirow[t]{2}{*}{ Parameters } & \multicolumn{3}{|c|}{ Univariate analysis } & \multicolumn{3}{|c|}{ Multivariate analysis } \\
\hline & Hazard.Ratio & $\mathrm{Cl} 195$ & Pvalue & Hazard.Ratio & $\mathrm{Cl} 195$ & Pvalue \\
\hline age & 1.63 & $1.19-2.24$ & 0.003 & 1.64 & $1.2-2.26$ & 0.002 \\
\hline subdivision & 0.84 & $0.67-1.04$ & 0.101 & & & \\
\hline stage & 1.09 & $0.8-1.5$ & 0.581 & & & \\
\hline longest dimension & 1.12 & $0.82-1.52$ & 0.485 & & & \\
\hline lymphatic invasion & 1.02 & $0.85-1.23$ & 0.798 & & & \\
\hline histologic grade & 1.12 & $0.88-1.42$ & 0.349 & & & \\
\hline sample type & 0.43 & $0.11-1.73$ & 0.235 & & & \\
\hline BCL7A & 1.51 & $1.13-2.03$ & 0.006 & 1.52 & $1.14-2.05$ & 0.005 \\
\hline
\end{tabular}

understand the role of BCL7A in ovarian cancer further.

BCL7A has been proven to have a close correlation with the prognosis of patients. Previous studies have found that early-stage cutaneous T-cell lymphoma patients with low expression of BCL7A were more likely to have a poor prognosis [8]. However, the association between BCL7A and overall survival was previously unknown in ovarian cancer. In this work, we found that the overall survival time was significantly shorter when ovarian cancer patients had low BCL7A expression. In addition, subgroup analysis found the same phenomenon in advanced stage, G3 and G4, and young patient and older patient groups.

To the best of our knowledge, this is the first study to examine the prognostic value of BCL7A expression in

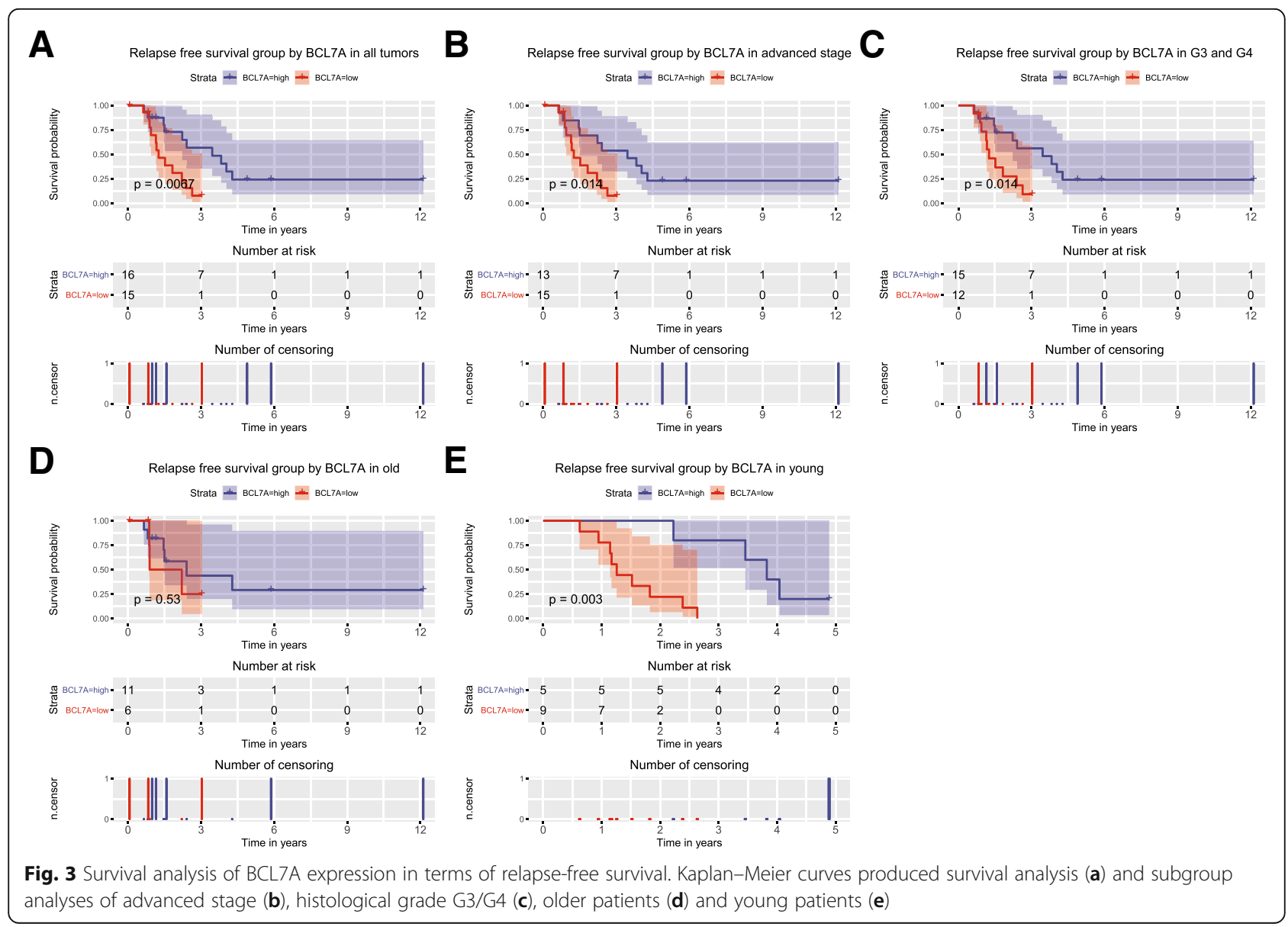


Table 4 Univariate and Multivariate Cox analysis of relapse-free survival in ovarian cancer

\begin{tabular}{|c|c|c|c|c|c|c|}
\hline \multirow[t]{2}{*}{ Parameters } & \multicolumn{3}{|c|}{ Univariate analysis } & \multicolumn{3}{|c|}{ Multivariate analysis } \\
\hline & Hazard.Ratio & $\mathrm{C} 195$ & Pvalue & Hazard.Ratio & $\mathrm{C} 195$ & Pvalue \\
\hline age & 0.71 & $0.3-1.67$ & 0.433 & & & \\
\hline subdivision & 0.92 & $0.34-2.48$ & 0.875 & & & \\
\hline stage & 1.92 & $0.78-4.71$ & 0.156 & & & \\
\hline longest dimension & 0.62 & $0.25-1.56$ & 0.311 & & & \\
\hline lymphatic invasion & 0 & $0-\operatorname{lnf}$ & 0.998 & & & \\
\hline histologic grade & 1.35 & $0.65-2.83$ & 0.421 & & & \\
\hline sample type & 1.47 & $0.19-11.3$ & 0.711 & & & \\
\hline BCL7A & 3.65 & $1.35-9.89$ & 0.011 & 3.65 & $1.35-9.89$ & 0.011 \\
\hline
\end{tabular}

ovarian cancer. Together with other studies on the functions of BCL7A, we have contributed to a better understanding of the role of BCL7A as well as a better possibility of achieving a precise prognosis. However, the underlying mechanism has not been completely explored. In the future, we will perform sophisticated vitro and vivo experiments to explore the mechanism in depth.

\section{Conclusion}

In conclusion, we generally focused on the prognostic value of BCL7A for ovarian cancer patients. Low BCL7A expression has been proven to be a distinct marker of patients with a poor prognosis. In the future, we plan to perform in vitro and in vivo experiments to explore the mechanism further.

\section{Materials and methods Data sources}

We have obtained currently available clinical and RNAseq data from both normal and cancerous ovarian tissues. Databases, including TCGA (https://cancergenome.nih.gov/) and GTEx (www.gtexportal.org/), were utilized. Level 3 data were downloaded from the databases. This dataset shows the gene-level transcription estimates, as in $\log 2(x+1)$ transformed RSEM normalized counts. There is no existing ethical conflict because all data we used in this study are permitted to be used in research.

\section{Data mining}

$\mathrm{R}$ (version 3.5.1) [16] was used for data mining. The ggplot2 package [17] was utilized to draw boxplots of clinical characteristics due to their expression variation. We used the median BCL7A expression as a cut-off to delineate the low vs high categories. The Chi-square test and Fisher's exact test were used for the evaluation of the possible clinical correlation between clinical features and BCL7A expression.
Survival package $[18,19]$ was used to draw survival curves, followed by log-rank tests to examine the survival deviation. Correlative variables were selected by a univariate Cox model, while the multivariate Cox model evaluated the independence of BCL7A rather than other clinical characteristics.

\section{Acknowledgements}

The results shown here are partly based upon data generated by the TCGA Research Network: https://www.cancer.gov/tcga.

\section{Funding}

This study was supported by Science and Technology of Jilin Province Health and Family Planning Commission Project 2017Q035(ZY).

Availability of data and materials

Not applicable.

\section{Authors' contributions}

JW contributed conception and design of the study. MH and YP were responsible for extracting data. ZS and LS conducted data analysis and wrote the first draft of the manuscript. ZY and JW contributed to manuscript revision and final approval for submission. All authors reviewed the manuscript and provided comments. All authors read and approved the final manuscript.

Ethics approval and consent to participate

Not applicable.

\section{Consent for publication \\ Not applicable.}

Competing interests

The authors declare that they have no competing interests.

\section{Publisher's Note}

Springer Nature remains neutral with regard to jurisdictional claims in published maps and institutional affiliations.

\section{Author details}

${ }^{1}$ Department of Gynaecology and Obstetrics, China-Japan Union Hospital of Jilin University, 126 Xiantai Street, Changchun 130033, People's Republic of China. ${ }^{2}$ Department of Breast Surgery, China-Japan Union Hospital of Jilin University, 126 Xiantai Street, Changchun 130033, People's Republic of China. ${ }^{3}$ Department of Anesthesia, The Second Hospital of Jilin University,

Changchun 130022, People's Republic of China. 
Received: 9 January 2019 Accepted: 29 April 2019

Published online: 10 May 2019

\section{References}

1. La Vecchia C. Ovarian cancer: epidemiology and risk factors. Eur J Cancer Prev. 2017;26(1):55-62

2. Doll KM, Pinheiro LC, Oncology RBJG. Pre-diagnosis health-related quality of life, surgery, and survival in women with advanced epithelial ovarian cancer: A SEER-MHOS study. Gynecol Oncol. 2017;144(2):348-53.

3. Eisenhauer EA. Real-world evidence in the treatment of ovarian cancer. Ann Oncol. 2017;28(null):viii61-viii5.

4. Khalique S, Banerjee S. Nintedanib in ovarian cancer. Expert Opin Investig Drugs. 2017;26(9):1073-81.

5. Mallen A, Soong TR, Townsend MK, Wenham RM, Crum CP. Surgical prevention strategies in ovarian cancer. Gynecol Oncol. 2018;151(1):166-75.

6. Ramos-Medina R, Montes-Moreno S, Maestre L, Cañamero M, RodríguezPinilla M, Martínez-Torrecuadrada J, et al. BCL7A protein expression in normal and malignant lymphoid tissues. 2013;160(1):106-109.

7. $\quad \mathrm{N} A, \mathrm{D} J, J \mathrm{M} \mathrm{H}, J \mathrm{~S}, \mathrm{EN}, \mathrm{K}$ T, et al. Molecular cloning of complex chromosomal translocation $t(8 ; 14 ; 12)(q 24.1 ; q 32.3 ; q 24.1)$ in a Burkitt lymphoma cell line defines a new gene (BCL7A) with homology to caldesmon. Blood. 1996;87(8):3124-34.

8. Litvinov IV, Youwen Z, Kupper TS, SJL D. Loss of BCL7A expression correlates with poor disease prognosis in patients with early-stage cutaneous T-cell lymphoma. Leuk Lymphoma. 2013;54(3):653.

9. Au KK, Josahkian JA, Francis JA, Squire JA, Koti M. Current state of biomarkers in ovarian cancer prognosis. Future Oncol. 2015;11(23):3187-95.

10. Hacker NF, Rao A. Surgery for advanced epithelial ovarian cancer. Best Pract Res Clin Obstet Gynaecol. 2017;41(undefined):71-87.

11. Marchetti C, De Felice F, Di Pinto A, D'Oria O, Aleksa N, Musella A, Palaia I, et al. Dose-dense weekly chemotherapy in advanced ovarian cancer: An updated meta-analysis of randomized controlled trials. Crit Rev Oncol Hematol. 2018;125(undefined):30-4

12. Kaeser MD, Aslanian A, Dong MQ, Yates JR 3rd. BRD7, a novel PBAF-specific SWI/SNF subunit, is required for target gene activation and repression in embryonic stem cells. J Biol Chem. 2008;283(47):32254-63.

13. Blenk S, Engelmann J, Weniger M, Schultz J, Dittrich M, Rosenwald A, Müller-Hermelink HK, et al. Germinal center B cell-like (GCB) and activated B cell-like ( $A B C$ ) type of diffuse large $B$ cell lymphoma (DLBCL): analysis of molecular predictors, signatures, cell cycle state and patient survival. Cancer Inform. 2007;3(undefined):399-420.

14. Tracey L, Villuendas R, Dotor AM, Spiteri I, Ortiz P, Garcia JF, Peralto JL, et al. Mycosis fungoides shows concurrent deregulation of multiple genes involved in the TNF signaling pathway: an expression profile study. Blood. 2003;102(3):1042-50.

15. Martinez-Delgado B, Meléndez B, Cuadros M, Alvarez J, Castrillo JM, Ruiz De La Parte A, Mollejo M, et al. Expression profiling of T-cell lymphomas differentiates peripheral and lymphoblastic lymphomas and defines survival related genes. Clin Cancer Res. 2004;10(15):4971-82.

16. Team RDCJC. R: A language and environment for statistical computing, vol. 14. Vienna: R Foundation for statistical computing; 2009. p. 12-21.

17. Wickham HJ. Ggplot2 :elegant graphics for data analysis. 2011;174(1):245-6.

18. Therneau TM. Modeling Survival Data: Extending the Cox Model. 2000; 97(457):353-4.

19. Terry TJRpv. A package for survival analysis in S. 2012:2.37-2.34

Ready to submit your research? Choose BMC and benefit from:

- fast, convenient online submission

- thorough peer review by experienced researchers in your field

- rapid publication on acceptance

- support for research data, including large and complex data types

- gold Open Access which fosters wider collaboration and increased citations

- maximum visibility for your research: over $100 \mathrm{M}$ website views per year

At BMC, research is always in progress.

Learn more biomedcentral.com/submissions 